Maxiselly, Y. A. Shohiboniawan $\cdot$ W. Sutari $\cdot$ N. Wicaksana $\cdot$ H. Syahrian

\title{
Respon beberapa klon bibit kina (Chinchona sp.) asal setek sambung dua spesies di berbagai media tanam
}

\section{Response of some cloned cinchona seedlings (Cinchona sp.) from grafting of two species in various planting medias}

Diterima : 11 Desember 2017/Disetujui : 18 Desember 2017 / Dipublikasikan : 30 Desember 2017

CDepartment of Crop Science, Padjadjaran University

\begin{abstract}
Cinchona is a plant, which is usually used as a medicine for various diseases, such as malaria and heart disease since it contains various alkaloids. Productivity improvement of cinchona plant is needed to support quality and quantity of natural medicine. One of important factors in quality of cinchona plant is good planting material. Planting material is also supported by suitability of planting media. All this time, the used planting media for cinchona has an obstacle in media weight that causes difficulty in distributing the seedlings. This research aims to identify new media that suits for planting material of cinchona. Planting material used 6 clones of Cinchona succirubra that was grafted with 1 Cinchona ledgeriana in 5 planting media's. Experiment method used simple Randomized Block Design (RBD) with two replications. Observation on 3 months old of cinchona seedling included survival rate plant, plant height, number of leaf, stem diameter, and number of shoot. The result showed that there is an effect on survival rate and stem diameter. Clone 1, 4, and 5 indicated good response in various planting media's at the variable. This research result showed that there is alternative planting media that can substitute traditional planting media for cinchona.
\end{abstract}

Keywords: C.ledgeriana, C.succirubra, Fluff, Topsoil,

\footnotetext{
Dikomunikasikan oleh Mira Ariyanti

Maxiselly, Y. ${ }^{1} \cdot$ A. Shohiboniawan ${ }^{2} \cdot$ W. Sutari ${ }^{1} \cdot$ N.

Wicaksana $^{1} \cdot$ H. Syahrian ${ }^{3}$

1) Dosen Departemen Budidaya Pertanian Fakultas

Pertanian, UNPAD

2) Mahasiswa Program studi Agroteknologi Fakultas

Pertanian UNPAD

3) Peneliti Pusat Penelitian Teh dan Kina Gambung

Korespondensi : yudithia.maxiselly@unpad.ac.id
}

Sari Kina merupakan tanaman yang selama ini dimanfaatkan sebagai obat berbagai penyakit, seperti malaria dan jantung karena memiliki kandungan alkaloid yang beragam. Peningkatan produktifitas tanaman kina dibutuhkan untuk menunjang kuantitas dan kualitas obat bahan alam. Salah satu faktor penting dalam kualitas tanaman kina adalah bahan tanam yang baik. Bahan tanam juga didukung dengan kecocokan media tanam. Media tanam yang selama ini digunakan pada pembibitan kina memiliki kendala di bobot media sehingga sulit untuk pendistribusian bibit. Penelitian ini bertujuan mencari media baru yang cocok untuk bahan tanam kina. Bahan tanam menggunakan 6 klon kina succi yang disambung dengan 1 jenis kina ledger pada 5 media tanam. Metode eksperimen menggunakan RAK sederhana yang diulang 2 kali. Pengamatan meliputi persentase hidup tanaman, tinggi tanaman, jumlah daun, diameter batang, dan jumlah tunas yang diamati saat bibit kina berumur 3 bulan. Hasil pengamatan menunjukkan terdapat pengaruh pada persentase tanaman hidup dan diameter batang. Klon 1, 4, dan 5 menunjukkan respon baik di berbagai media tanam pada variabel tersebut. Hasil penelitian ini menunjukkan adanya media alternatif yang dapat menggantikan media tanam kina yang selama ini digunakan.

Kata Kunci : C.ledgeriana, C.succirubra, Fluff, Topsoil,

\section{Pendahuluan}

Kina merupakan tanaman tahunan penghasil obat-obatan alam karena kandungan alkaloidnya terutama kinine dan kinidine. Kina selama ini dapat diperbanyak baik secara generatif maupun vegetatif. Cara vegetatif dinilai lebih 
efektif karena waktu yang cepat dan memiliki sifat yang sama dengan induknya, selain itu kelemahan antar tanaman dapat diatasi dengan kombinasi sifat-sifat tanaman yang digabungkan seperti ketahanan terhadap penyakit meningkat (Sari dan Susilo, 2012), juga meningkatkan sifatsifat unggul lain yang sulit diperoleh dari generatif seperti produktivitas dan kualitas (Tambing dkk, 2008).

Klon kina yang menghasilkan alkaloid yang tinggi adalah kina ledger, jenis ini biasa digunakan sebagai batang atas dalam setek sambung. Kina ledger ini memiliki sifat rentan terhadap penyakit, sehingga perlu dikombinasikan dengan klon batang bawah yang tahan terhadap penyakit yaitu kina succi (Sukasmono, 1995). Masalah pada klon succi adalah terdapat beberapa jenis klon succi yang penyembuhan lukanya lama dan pertumbuhan akar lambat (Sriyadi, 2007). Hal ini menjadikan seleksi klon batang bawah diperlukan untuk meningkatkan kualitas bahan tanam kina.

Media tanam merupakan salah satu hal penting untuk mendukung pertumbuhan tanaman. Media yang tepat akan menjadi daya dukung yang baik untuk pertumbuhan akar bahan tanam asal vegetatif. Bahan tanam kina yang cocok pada media tanam akan mampu beregenerasi baik dan memiliki kemampuan membentuk kalus (Dalimoenthe, 2014). Media tanam yang biasa digunakan untuk menunjang pembibitan kina adalah topsoil Andosol. Permasalahan dari media tersebut adalah mulai terbatasnya tanah Andosol dan bobot tanah yang tinggi sehingga menyulitkan untuk pendistribusian bibit. Penelitian Dalimoenthe (2014), mendapatkan media tanam yang baik seperti serabut kelapa dan serbuk gergaji untuk pertumbuhan bibit kina ledger Cib 5. Berdasarkan hal tersebut diperlukan seleksi media tanam dan klon succi sebagai batang bawah melalui uji kompatibilitas terhadap batang atas untuk meningkatkan kualitas bahan tanam kina.

\section{Bahan dan Metode}

Penelitian ini dilaksanakan di Pusat Penelitian Teh dan Kina Gambung Kecamatan Pasir Jambu Kabupaten Bandung Jawa Barat mulai Februari - Oktober 2017. Lokasi percobaan berada pada ketinggian $1.300 \mathrm{mdpl}$, curah hujan tipe B berdasarkan klasifikasi Schmidt Fergusson.
Bahan yang akan digunakan dalam penelitian ini adalah satu klon ledger kina sebagai batang atas dan 6 klon succi sebagai batang bawah asal PPTK Gambung. Polibeg ukuran $15 \mathrm{~cm} \times 20 \mathrm{~cm}$, media tanam berupa kompos daun teh (fluff), serbuk gergaji, cocopeat, dan topsoil tanah Andosol, plastic grafting, pisau grafting. Penelitian ini menggunakan metode eksperimental, rancangan percobaan adalah Rancangan Acak Kelompok yang terdiri dari 30 perlakuan yaitu kombinasi 6 klon succi (Chinchona succirubra) tanaman kina asal PPTK Gambung yang disambung dengan satu klon ledger (Chinchona ledgeriana) pada 5 media tanam sebagai topsoil yaitu kontrol (topsoil tanah ndosol 100\%), serbuk gergaji 50\% + topsoil Andosol 50\%, serbuk gergaji $75 \%+25 \%$ tanah Andosol, cocopeat 25\% + tanah Andosol 75\%, fluff 50\% + tanah Andosol 50\% dan diulang dua kali sehingga terdapat 60 plot percobaan. Setiap perlakuan terdiri dari 8 tanaman sehingga total tanaman adalah 480 tanaman. Komponen yang diukur adalah komponen pertumbuhan berupa persentase tanaman hidup, tinggi tanaman, diameter batang atas dan jumlah daun. Pengamatan dilakukan pada umur 3 bulan setelah penyungkupan. Uji statistik yang digunakan untuk mengetahui pengaruh dari masing-masing perlakuan adalah uji $\mathrm{F}$ taraf $5 \%$ dan uji lanjut dilakukan bila ada variabel yang berbeda nyata dengan menggunakan uji Skotnot pada taraf nyata $5 \%$.

\section{Hasil dan Pembahasan}

Media tanam yang digunakan pada penelitian ini dianalisis terlebih dahulu sebelum digunakan sebagai media pembibitan. Hasil analisis dapat dilihat pada Tabel 1, kandungan $\mathrm{pH}$ masing-masing media bervariasi mulai dari asam sampai agak asam namun masih merupakan rentang $\mathrm{pH}$ yang cocok untuk tanaman kina. Tanaman kina memiliki rentang toleransi pH media tanam 4,6 -6,5 (Kartawijaya, 1995). Nilai $\mathrm{C} / \mathrm{N}$ pada media yang digunakan berkisar antara 5,56 - 14.7, menurut Badan Litbang Pertanian (2013), nilai C/N termasuk baik jika $<20$. Nilai $\mathrm{C} / \mathrm{N}$ yang terlalu tinggi akan menyebabkan aktivitas biologi mikroorganisme akan terhambat (Widarti dkk, 2015). Kandungan unsur lainnya pada media tanam yang digunakan tergolong baik sehingga dapat digunakan sebagai media pembibitan. 
Tabel 1. Analisis Kandungan Limamedia Tanam Pada Pembibitan Tanaman Kina.

\begin{tabular}{llcccccc}
\hline No & \multicolumn{1}{c}{ Media } & $\mathrm{pH} \mathrm{H}_{2} \mathrm{O}$ & $\begin{array}{c}\text { C.Org } \\
(\%)\end{array}$ & $\mathrm{C} / \mathrm{N}$ & $\begin{array}{c}\text { N.total } \\
(\%)\end{array}$ & $\begin{array}{c}\mathrm{P}_{2} \mathrm{O}_{5} \\
(\mathrm{ppm})\end{array}$ & $\begin{array}{c}\mathrm{K} \\
(\mathrm{mg} / 100 \mathrm{~g})\end{array}$ \\
\hline 1 & Andisol 100\% & 4.9 & 4.45 & 9.51 & 0.468 & 1.32 & 14.6 \\
2 & Fluff 50\% + Andisol 50\% & 5.1 & 6.34 & 5.56 & 1.14 & 19.6 & 218 \\
3 & Cocopeat 50\% + Andisol 50\% & 6.1 & 6.30 & 13.1 & 0.482 & 22.7 & 84.5 \\
4 & Serbuk gergaji 50\% + Andisol 50\% & 5.9 & 6.54 & 14.2 & 0.460 & 31.7 & 126 \\
5 & Serbuk gergaji 75\%+ Andisol 25\% & 5.1 & 6.79 & 14.7 & 0.461 & 26.3 & 91.3 \\
\hline
\end{tabular}

Ket : Diuji di Lab PPTK Gambung, 2017

Tabel 2. Pengaruh Berbagai Media Tanam terhadap Bibit Kina Usia 3 Bulan.

\begin{tabular}{llclll}
\hline No & Parameter Pengamatan & F hit & F tabel & Sig & CV $(\%)$ \\
\hline 1 & Persentase hidup & 2.89 & 1.8 & $*$ & 24.82 \\
2 & Tinggi tanaman & 0.67 & 2.03 & tn & 15.91 \\
3 & Jumlah daun & 0.73 & 2.05 & tn & 18.06 \\
4 & Diameter batang & 2.07 & 2.05 & $*$ & 6.05 \\
5 & Jumlah tunas & 1.15 & 2.05 & tn & 20.05 \\
\hline
\end{tabular}

Ket : th : tidak nyata , ${ }^{*}=$ nyata pada taraf $5 \%, \mathrm{CV}=$ Coeficient variation,

Tabel 2 merupakan hasil analisis varians perlakuan pada parameter pertumbuhan bibit kina usia 3 bulan, atau setelah sungkup boleh dibuka. Hasil tersebut dapat dikatakan valid karena nilai CV menunjukkan antara 6.05-24.82, menurut Gasperz (2006), pengaruh lingkungan dikatakan kecil pada percobaan saat nilai CV < $20 \%$. Pengaruh lingkungan yang sedikit besar terjadi pada parameter persentase tanaman hidup dan jumlah tunas. Pengaruh perlakuan ditunjukkan pada parameter persentase tanaman hidup dan diameter batang, sedangkan parameter lainnya tidak tampak pengaruh perlakuan. Hal ini dapat terjadi karena pengaruh media belum terlihat pada kina usia 3 bulan terutama terhadap parameter tinggi tanaman, jumlah daun dan jumlah tunas. Kina merupakan salah satu tanaman tahunan yang memiliki respon yang lama untuk pertumbuhannya. Persentase tanaman hidup menunjukkan kesesuaian bahan tanam terhadap media tanam, pada kina yang mengalami penyambungan antara batang atas dan batang bawah sering terdapat inkompatibilitas sehingga pertumbuhan daerah penyambungan tidak baik dan mengalami hambatan translokasi hara mineral (Dalimunthe, 2014). Penelitian Maxiselly dkk (2017) tentang komposisi bahan organik di kina TBM telah menunjukkan hasil berpengaruh terhadap karakter lilit batang, hal ini mendukung bahwa terdapat respon tanaman kina terhadap bahan organik yang membentuk pembesaran batang kina.

Hasil uji lanjut pada dua parameter tersebut tersaji pada Tabel 3. Persentase hidup tanaman kina 3 bulan dengan berbagai media tanam memiliki rentang hasil antara $0-93,75 \%$, artinya ada tanaman kina yang mati pada seluruh ulangan. Hasil ini menunjukkan adanya 2 kelompok perlakuan yang bernotasi a dan bernotasi b. Notasi $b$ dimulai dari nilai persentase hidup $37.5 \%$ pada perlakuan klon succi 4 dengan media serbuk gergaji 50\%. Klon yang menunjukkan respon baik pada media tanam yang diuji adalah succi 1 , succi 4, dan succi 5 pada seluruh media tanam yang dikombinasikan. Klon yang tidak mampu beradaptasi pada seluruh media tanam adalah succi 6 yang banyak mengalami kematian sehingga tidak dilanjutkan untuk pengamatan pada parameter selanjutnya.

Media tanam yang juga memiliki hasil yang baik seperti kontrol ditunjukkan pada fluff $50 \%$ yang memiliki persentase tanaman hidup dan diameter batang yang lebih baik pada beberapa klon. Fluff merupakan limbah pabrik teh yang dapat dimanfaatkan sebagai bahan organik pada tanaman. Menurut Rosniawaty dkk (2014), kompos asal limbah teh yang digunakan pada pembibitan teh usia 3 bulan menunjukan pengaruh baik pada parameter persentase tanaman hidup, karena sifat bahan organik ini yang ber $\mathrm{pH}$ rendah dan memiliki kandungan unsur hara yang sesuai. 
Tabel 3. Pengaruh Klon dan Media Tanam pada Presentasi Hidup dan Diameter Batang Bibit Kina Usia 3 Bulan.

\begin{tabular}{clcc}
\hline No & \multicolumn{1}{c}{ Perlakuan } & Presentasi Hidup (\%) & Diameter Batang (cm) \\
\hline 1 & Succi 1 media kontrol & $93,75 \mathrm{~b}$ & $0,72 \mathrm{~b}$ \\
2 & Succi 2 media kontrol & $25,00 \mathrm{a}$ & $0,61 \mathrm{a}$ \\
3 & Succi 3 media kontrol & $50,00 \mathrm{~b}$ & $0,67 \mathrm{a}$ \\
4 & Succi 4 media kontrol & $68,75 \mathrm{~b}$ & $0,77 \mathrm{~b}$ \\
5 & Succi 5 media kontrol & $62,50 \mathrm{~b}$ & $0,68 \mathrm{~b}$ \\
6 & Succi 6 media kontrol & $25,00 \mathrm{a}$ & - \\
7 & Succi 1 media serbuk gergaji 75\% & $43,75 \mathrm{~b}$ & $0,71 \mathrm{~b}$ \\
8 & Succi 2 media serbuk gergaji 75\% & $25,00 \mathrm{a}$ & $0,71 \mathrm{~b}$ \\
9 & Succi 3 media serbuk gergaji 75\% & $50,00 \mathrm{~b}$ & $0,65 \mathrm{a}$ \\
10 & Succi 4 media serbuk gergaji 75\% & $31,25 \mathrm{a}$ & $0,71 \mathrm{~b}$ \\
11 & Succi 5 media serbuk gergaji 75\% & $43,75 \mathrm{~b}$ & $0,66 \mathrm{a}$ \\
12 & Succi 6 media serbuk gergaji 75\% & $6,25 \mathrm{a}$ & - \\
13 & Succi 1 media serbuk gergaji 50\% & $62,50 \mathrm{~b}$ & $0,64 \mathrm{a}$ \\
14 & Succi 2 media serbuk gergaji 50\% & $25,00 \mathrm{a}$ & - \\
15 & Succi 3 media serbuk gergaji 50\% & $31,25 \mathrm{a}$ & $0,61 \mathrm{a}$ \\
16 & Succi 4 media serbuk gergaji 50\% & $37,50 \mathrm{~b}$ & $0,69 \mathrm{~b}$ \\
17 & Succi 5 media serbuk gergaji 50\% & $68,75 \mathrm{~b}$ & $0,68 \mathrm{~b}$ \\
18 & Succi 6 media serbuk gergaji 50\% & $0,00 \mathrm{a}$ & - \\
19 & Succi 1 media CCOPEAT 25\% & $87,50 \mathrm{~b}$ & $0,72 \mathrm{~b}$ \\
20 & Succi 2 media CCOPEAT 25\% & $18,75 \mathrm{a}$ & - \\
21 & Succi 3 media CCOPEAT 25\% & $43,75 \mathrm{~b}$ & $0,62 \mathrm{a}$ \\
22 & Succi 4 media CCOPEAT 25\% & $50,00 \mathrm{~b}$ & $0,69 \mathrm{~b}$ \\
23 & Succi 5 media CCOPEAT 25\% & $62,50 \mathrm{~b}$ & $0,64 \mathrm{a}$ \\
24 & Succi 6 media CCOPEAT 25\% & $12,50 \mathrm{a}$ & - \\
25 & Succi 1 media Fluf 50\% & $93,75 \mathrm{~b}$ & $0,66 \mathrm{a}$ \\
26 & Succi 2 media Fluf 50\% & $18,75 \mathrm{a}$ & $0,69 \mathrm{~b}$ \\
27 & Succi 3 media Fluf 50\% & $18,75 \mathrm{a}$ & $0,67 \mathrm{a}$ \\
28 & Succi 4 media Fluf 50\% & $43,75 \mathrm{~b}$ & $0,74 \mathrm{~b}$ \\
29 & Succi 5 media Fluf 50\% & $75,00 \mathrm{~b}$ & $0,70 \mathrm{~b}$ \\
30 & Succi 6 media Fluf 50\% & $12,50 \mathrm{a}$ & - \\
\hline & $5 a \mathrm{a} \%$ & \\
\hline
\end{tabular}

Keterangan : angka yang diikuti huruf yang berbeda pada kolom yang sama berpengaruh nyata pada taraf $5 \%$ berdasarkan uji Skotnot.

\section{Kesimpulan}

Media tanam yang digunakan pada penelitian ini memiliki kandungan hara yang baik. Media tanam dan klon kina berpengaruh pada persentase tanaman hidup dan diameter bibit kina usia 3 bulan. Klon kina 1,4 dan 5 menunjukkan hasil yang lebih baik pada parameter persentase tanaman hidup dan diameter batang. Media tanam yang menunjukkan tendensi sama baiknya seperti tanah Andisol pada pembibitan kina adalah fluff.

\section{Daftar Pustaka}

Badan Litbang Pertanian. 2013. Pengomposan Jerami. Agroinovasi Sinartani. Edisi 22-28 Mei 2013 No.3508 Tahun XLIII di akses pada 6 Nov 2017 di http://www. litbang.pertanian.go.id/download/one/38 4/file/PENGOMPOSAN-JERAMI.pdf

Dalimoenthe S.L. 2014. Pengaruh media tanam organik terhadap pertumbuhan dan perakaran pada fase awal benih kina (Cinchona ledgeriana Moens) di persemaian. Jurnal Penelitian Teh dan Kina, 17(2), 2014: 57-70

Gaspersz V. 2006. Teknik Analisis Dalam Penelitian Percobaan. Tarsito. Bandung.

Kartawijaya W.S. 1995. Petunjuk Kultur Teknis Tanaman Kina: Syarat Tumbuh. PPTK Gambung.

Maxiselly, Y., M. Ariyanti dan M.A. Soleh. 2017. Respon tanaman kina (Chinchona sp.) fase TBM terhadap berbagai kombinasi pupuk organik dan anorganik di Jatinangor Sumedang. Jurnal Agrotek Indonesia 2(2) 70-72

Rosniawaty S, IRD. Anjarsari, C. Suherman, dan Y.Maxiselly. 2014. Pemanfaatan limbah pabrik teh sebagai media tanam setek teh 
di dataran rendah. Prosiding SEMNAS Sistem Pertanian Bioindustri Berkelanjutan UPN Veteran 11 Desember 2014

Sari I.A. dan A.W. Susilo.2012. Keberhasilan sambungan pada beberapa jenis batang atas dan family batang bawah kakao (Theobroma cocoa L.). Pelita Perkebunan 28(2) 2012, 72-81

Sriyadi B. 2007. Seleksi kesesuaian batang atas kina ledger klon QRC dengan batang bawah kina succi klon SG1 dalam pembibitan. Jurnal Penelitian Teh dan Kina 10(3) :99-106
Sukasmono. 1995. Petunjuk Kultur Teknis Tanaman Kina: Pendahuluan. PPTK Gambung.

Tambing Y, E. Adelina, T. Budiarti, dan E. Murniati. 2008. Kompatibilitas batang bawah nangka tahan kering dengan entris nangka asal sulawesi tengah dengan cara sambung pucuk. J. Agroland 15 (2) : 95 - 100,

Widarti B.N, W. K. Wardhini, dan E. Sarwono. 2015. Pengaruh rasio $\mathrm{C} / \mathrm{N}$ bahan baku pada pembuatan kompos dari kubis dan kulit pisang. Jurnal Integrasi Proses Vol. 5, No. 2 Hal. 75 - 80 